\title{
Afterthought of the Old Summer Palace Restoration-Study on Protection and Development of the Chinese Landscape Cultural Heritage Based on Ontology
}

\author{
Wei-le JIANG ${ }^{1, a}$ and Chen-chen $\mathrm{MA}^{2, \mathrm{~b}}$ \\ ${ }^{1}$ Institute of heritage sites \& historical architecture conservation, Xi'an Jiaotong \\ University \\ Room 1106,Building 5, Village 1,Xianning West Road 28,Xi'an,Shannxi,China \\ ${ }^{2}$ College of electrical engineering, Xi'an Jiaotong University \\ Room 401,Building 43,Village1,Xianning West Road 28,Xi'an,Shannxi,China \\ ajiangwl@xjtu.edu.cn, ${ }^{b}$ chenchen_m@xjtu.edu.cn
}

Keywords: The old summer palace, Landscape cultural heritage, Ontology.

\begin{abstract}
The development and protection of the Old Summer Palace (Yuan Ming Yuan) in Beijing China have received extensive attention in China and even in the whole world. According to social surveys, tourists have been found that it is never to form whole memory of the Old Summer Palace. The urbanization and improper protection threat the integrity of the Old Summer Palace ruins. Their artistic value, cultural value, historical value is gradually weakening, and becoming disappeared from human memory.

Visual stimuli is the main style of landscape perception, however, vast Chinese gardens used to be on the Old Summer Palace ruins, almost did not leave any physical entity element that can convey the landscape features, so many tourists ignored the Old Summer Palace has real artistic value as the essence of Chinese traditional gardens. It is a big issue if we maintain the destroyed status or restore it?

Orientals learn and accept the rules and methods for cultural heritage protection proposed by Westerners, and then they continue examining and understanding their own culture. "NARA Declaration", means that Orientals redefine the concept of their own culture and values about "Being" as a matter of cultural heritage protection and standard development. This paper proposes that regeneration is one of the most important ways to excavate Chinese culture if landscape cultural heritage could be an ontological issue. For regeneration, we should pay attention on survival process, and not too much on death souvenir. Because Chinese culture emphasizes reincarnation, the energy of life maintenance, but the form of life is not necessarily the same, because of the life style is from generation to generation.

This paper is based on the premise of sustainable development and globalization in the modern world. The Old Summer Palace in Beijing is as the object and we discuss from the perspective of Eastern philosophy of landscape and cultural heritage protection and development. Based on ontology research, this paper can give suggestions about landscape preservation and development of cultural heritage in China, and even we can make contribution for cultural tourism of China.
\end{abstract}

Comment:

The Old Summer Palace, known in Chinese as Yuan Ming Yuan (the Gardens of Perfect Brightness), and originally called the Imperial Gardens. Beijing, China 


\section{Main Text:}

The word "ontology" originally from Greece was first used by the Guokelanniu(Goclenius, 1547-1628) in the 17th century. "Existence" is abstract, rational and prior instead of inexperienced, and it is established on the basis of the so-called philosophy. While having established a logical foundation, it is different from man's life and experience including men's test of themselves or the whole. However, people can directly feel and experience the Chinese "ontology" which is a dynamic source of creating lives instead of an abstract thing.

Cheng Zhongying, a professor in the department of philosophy of the Hawaii University, said in a seminar that "ontology" is a core concept in the Chinese philosophy, and it includes the thought of "Ben" and 'Ti". "Ben" refers to the origin, namely time; "Ti" refers to the whole, namely the system, space and the externality. The Chinese ontology is conclusive, broad and profound[1].

As is well-known, the existence of the cities in the world is different and changes with teh time, therefore we can say cities are the proofs of geography and history. The human society has specific requirements on the existence of the cities they live. It is because of the definite attitude that a comparative and different era appears under the historical and cultural differences. The comparison helps to highlight the attitude of the West. I think the protection of the cultural heritages in the "Convention Concerning the Protection of the World Cultural and Natural Heritage" approved by the UNESCO (United Nations Educational Scientific and Culture Organization) in 1972 is not universal. Some expressing methods in the "Convention" are different in different countries, because "protection" means different practice. To conduct the protection all around the world is infeasible, even in Europe, because it is contrary to the theories of their Cultural Sector which shows the typical attitudes of the West in the modern times. However, we should not forget that it is because of the idea of global construction proposed by some Western hegemonism in the modern history that leads to the deficit in the cultural cognition in many places around the world. Martin Heidegger said: "only if we do not try to fill a thing in the concept we made will it show itself to us ". "From BC544 to 450, the Europeans had been emphasizing the matter, but the Chinese people had been emphasizing changes and relations" [2].The appearance of "The Declaration in Nara" shows that the Oriental people reinterpret the word "existence" in their own civilization and values and put forward another standard of protecting and developing the cultural heritages.

With the improvement of the Chinese economy and people's living standards, the protection of the Chinese cultural heritages enjoys more and more attention of the government and the civilian. The protection of the cultural heritages is to preserve country history. The soul of a nation and the spiritual home of the Chinese.

In the protection of the Chinese cultural heritages, we get experience as well as lessons. Today all the country and people are willing to show more respect to culture and put the development of it on an unprecedented place. On October, 15th ,2011, the six plenary session of the seventeen session of the Central Committee of the people's Republic of China passed "The Decision Made by the Central Committee of the Communist Party to Deepen Culture System Reforms and Enhance the Development of Socialist Culture ”, in which clearly includes the following :" building an inheriting system for the brilliant culture. The brilliant culture agglomerates the perseverant spiritual pursuit of the Chinese nation and replenished spiritual wealth, and it provides a profound foundation for the development of the advanced socialist culture and an important support of building a common spiritual home for the Chinese 
nation. We should be fully aware of the traditional Chinese culture, absorb what is best and eliminate what is bad, let the ancient serve the modern, bring forth the new through the old, attach equal importance to utilization, popularization and promoting. We should enhance our understanding and exploration of the values and thoughts of the brilliant traditional culture, and maintain the basic elements of the national culture to make the brilliant traditional culture become the spiritual power that inspires people to make more progress in the new times. We should strengthen the development of the great cultural and natural heritage site, national key cultural unit, the historically famous cities, towns and villages. We should strengthen the protection and inheriting of the intangible cultural heritage[3]." It is very important for the Chinese cultural renovation and symbolizes that China, the second great country of economic entity in the world, has raised the cultural development and revivification to a new place and level.

Recalling the past, "we couldn't erase our footprints", some destruction have been made. If we take a broad view of the whole China, the cities are becoming similar to each other, which remind people that the rejuvenation of the Chinese culture and the protection of the landscape heritages and the architecture heritages are extremely urgent.

The explanation of the order and freedom in landscapes is not an easy question. The order and freedom of the Oriental and the Occidental under two different philosophical systems are essentially different, which represent in the landscapes. In the Western gardens, especially the traditional gardens, there are straight espaliers, geometric patterns and symmetrical characteristics, etc, in the layout. The trim, size, height, width or color of the plants should follow the rules, which represent the order. The exterior represent disorder, but the interior represent order, regularity and stability[4].

In the Oriental, the rites of the Confucianism are ubiquitous, especially in the field of architecture, in which everything should follow the standard of rites, no matter singlely or in groups. The word "freedom" is not appropriate to be used in "coming into being" for the Oriental world. In the society, people should follow rites and laws, and subordinate to the collective, namely" man should be obedient to his parents at home and loyal to his monarchy outside". However, "freedom" is unacceptable to some sense. However, the garden landscape in the interior residence becomes the only paradise for men to enjoy the spiritual freedom that comes from Taoism. This kind of freedom is used for "cultivating one's moral character" and represent in the landscape, regardless of its scale and size. Zong Bin in the Southern Dynasties (AD 420-589) mentioned "reason" in "Landscape Painting", namely to appreciate reason with mind, one will better understand it". If we appreciate the soul of the landscape with our eyes, we will understand and get the "sense". Therefore, if the paintings are vivid, what the observers and the painters see and understand from the picture are the same. What we see and understand come from the landscape. The spirits of the observers and painters can detach from the earthliness, and they can get the "rites", which can explain why the Chinese people love landscape painting and the micro landscape appears in the gardening, and why there is "Dry Landscape" in Japan. The landscape in Japan serves for expressing emotions. As Heidegger described "existence" which will change in different places, time and space. I think this corroborates with " circumstances changes with mind "[5].

Noumenon is a dynamic and creative origin. The relationship between noumenon and ontology is Yin and Yang. For example, as an abstract concept, "nation" has its history and culture. Abstract and concrete are combined. Noumenon has standardized forms and represent in the standardized behaviour and requirements. From this perspective, it is logical; 
while in practice, to put this standard into practice is practical and historical. In short, for the Old Summer Palace, we can conclude "existence" as its history and culture, including the original intention of building the Old Summer Palace, its historical values, value use, and the value of time, artistic value and the relative artistic value. We can also regard "style"as the existence of the Old Summer Palace, such as the initial existence, the existence in use, the existence when it was ruined, and the existence after it was destroyed. The existence after the destruction has continued until now, and can it best describe the history and culture of the Old Summer Palace? Is it reasonable to continue the existence after destruction? Does this existence correspond to the "basis"? If not, we should try our best to realize the unification of the ontology, namely the unification of the history, culture and existence of the Old Summer Palace.

Why could we say like this, because the Chinese people attach great importance to the "concept" which refers to annotation? Annotation is not only the language use but also a way of perceptually mastering things. I believe "concept" is an important way to explain ontology which exists in annotation. To fix the state of the Old Summer Palace is a way of annotation, but is it the best and only way to explain ontology, possibly not. The practice of "basis" is superior to the fixation of it in the destructed state, because destruction is only a phase instead of an end in the history of the Old Summer Palace, like we need ontology to explain things. If we need to assume the ontology, it is more similar to the basis (Ben) as the existence of logic. But as the existence of history, the basis should combine with the concept. As for how to put the "basis" of the Old Summer Palace into practice and gain good results and how to deal with "concept", we should be more cautious.

As to the restoration, we should be kind to the original state and should not miss the process of being destroyed. The more you are kind to the original state, the easier you will replace it with the future ideals. it is the real purpose of restoration in China's landscape heritage, because most of the landscape heritage in the culture heritage circle are often considered as a perpetual souvenir. In the culture heritage circle, more work related to ruins is historical protection and reservation. Therefore I think it is not appropriate. It is meaningless only to talk about the word: "protection". There are many Western culture based on perpetuity in the planning. The Western culture has two basic elements, namely the absolute truth and the perfect men. Therefore, one generation thinks that their exploration of the absolute truth is closer than that of the previous generation, so he will keep it forever, which is a foundation of the Western cities, architectural and landscapes theories. However, the Chinese culture is different which emphasizes transmigration. The energy of life is continuing, but its form may be different. We pass on our lifestyles to one generation after another, and the Chinese culture is based on the relations instead of the fixed souvenirs. I believe the traditional meaning of the restoration has a strong sense of the Chinese culture.

\section{Acknowledgement}

(1)This research was financially sponsored by national natural science foundation: Masonry structure ancient architecture multi-level information extraction and processing in complicated environment, a number of basic theory and key technology research. (Project No: 51541804). 
(2)This research was financially sponsored by the basic research project of Natural Science in Shaanxi Province: The research on the protection of the cultural heritage and the landscape diversity in Qinling Mountains region. (Project No: 2014JQ7283).

(3)This research was financially sponsored by the basic scientific research project of Xi'an JiaoTong University: The research of digital image processing technology in the protection and restoration of Architectural Culture Heritage. (Project No: 1191320065).

\section{References}

[1] Zhongying Cheng, From the Chinese and Western mutual interpretation of stand:Chinese philosophy and the new positioning of the Chinese culture., China Renmin University Press.Beijing.2005.p.19. (In Chinese)

[2] Heidegger Martin. Being and Time, Trans. Chen Jiaying, Wang Qingjie. Beijing: SDX Joint Publishing Company, 1999. (In Chinese)

[3] The Central Committee of the people's Republic of China 'The Decision Made by the Central Committee of the Communist Party to Deepen Culture System Reforms and Enhance the Development of Socialist Culture". vol 2. 2011. (In Chinese)

[4] Maria Adriana Giusti, Materials and Symbols - garden vs landscape., Edizioni ETS, 2010, Pisa, 2010, p15.

[5] Huayan Jing, buddhavatam sakamahavaipu-lyasutra., Buddhist scriptures.(In Chinese) 